\title{
Variation in Resistance of Populus nigra to Sphaerulina musiva in the North-Central United States
}

Kelsey L. Dunnell, Department of Botany and Plant Pathology, Oregon State University, Corvallis 97331; Bill Berguson and Bernard McMahon, Natural Resources Research Institute, Duluth, MN 55811; and Jared M. LeBoldus, Department of Plant Pathology, North Dakota State University, Fargo and Department of Botany and Plant Pathology, Oregon State University, Corvallis 97331

\begin{abstract}
Dunnell, K. L., Berguson, B., McMahon, B., and LeBoldus, J. M. 2016. Variation in resistance of Populus nigra to Sphaerulina musiva in the northcentral United States. Plant Dis. 100:287-291.

Populus nigra, commonly used in hybrid poplar breeding programs in the north-central United States, is susceptible to Septoria stem canker, caused by Sphaerulina musiva. In this study, two experiments were conducted to (i) characterize the variation in resistance of 47 genotypes of $P$. nigra collected from seven locations in Europe in terms of cankers per centimeter and disease severity score; (ii) determine whether location, isolate, genotype, or their interactions significantly affect cankers per centimeter and disease severity score; and (iii) examine the correlation of disease severity score between single-isolate and bulk-isolate inoculations. The majority of the

variation in resistance for cankers per centimeter was explained by location (72\%; $P<0.001)$ followed by genotype(location) $(28 \% ; P<0.001)$. In contrast, the majority of the variation in disease severity score was explained by genotype-location $(51 \% ; P<0.001)$ followed by location $(26 \%$; $P=0.025)$. The disease severity score model also indicated the presence of a significant isolate effect $(P=0.034)$ and genotype(location $) \times$ isolate interaction $(P=0.004)$. The correlation coefficients for disease severity score indicated a significant range of correlations $(r=0.871$ to $r=0.952)$ when correlating single-isolate to bulk-isolate inoculations.
\end{abstract}

Populus spp. and their hybrids are commonly used for fiber production and have tremendous potential as a bioenergy feedstock in North America (Dickmann et al. 2001). This potential is largely due to their rapid growth rate, ease of clonal propagation, and ability to grow across a range of environmental conditions (Bisoffi and Gullberg 1996). In addition, hybridization of Populus spp. allows breeders to combine desirable traits and exploit heterosis (i.e., hybrid vigor) typically associated with these trees (Bisoffi and Gullberg 1996). In the north-central and eastern United States, Populus nigra L. (black poplar), a native tree species of Eurasia, is an important parent used in hybrid poplar breeding programs (Dickmann et al. 2001). This species has been used in interspecific crosses with $P$. deltoides Bartr. ex Marsh. in order to incorporate desirable traits such as rootability and vigorous stump sprouting in hybrid progeny (Dickmann et al. 2001). However, growth and yield of these hybrids can be affected by disease.

Septoria leaf spot and stem canker, caused by the fungus Sphaerulina musiva (Peck) Quaedvl., Verkley \& Crous (syn. = Septoria musiva Peck), is the most economically important disease and the major limiting factor to the production of Populus spp. as a commercial crop for fiber and biofuel (Feau et al. 2010; Newcombe and Ostry 2001; Ostry and McNabb 1985). The leaf-spot disease causes premature defoliation and a reduction in photosynthetic capacity of susceptible genotypes, potentially reducing yield (Bier 1939). However, it is the stem canker which has the greatest impact on hybrid poplar production because girdling cankers weaken stems, increasing the risk of wind breakage or killing trees outright (Bier 1939; Ostry and McNabb 1985; Waterman 1954). Annual biomass losses due to Septoria infection can be as high as $63 \%$ of total yield (Lo et al. 1995). In one region of the United States where 10,000 ha of a single susceptible variety were planted, a survey indicated that $>90 \%$ of trees were infected and $74 \%$ had major stem damage (Weiland and Stanosz 2003).

Corresponding author: J. M. LeBoldus;

E-mail: Jared.LeBoldus@ science.oregonstate.edu

Accepted for publication 2 September 2015.

http://dx.doi.org/10.1094/PDIS-05-15-0516-RE

(C) 2016 The American Phytopathological Society
In Michigan, 5 years after planting, $86 \%$ of the trees had Septoria cankers and, 2 years later, 69\% had broken tops (Ostry and McNabb 1985). In a trial with 56 genotypes of $P$. balsamifera, all trees had at least one stem canker per stem 7 years after planting (LeBoldus et al. 2009). Similar affects have been observed in other studies. In addition, this pathogen, endemic to eastern and central North America (Feau et al. 2010), has been reported for the first time in the Pacific Northwest (Callan et al. 2007), Argentina (Ares and Gutierrez 1996), Brazil (Santos et al. 2010), and Asia (Teterevnikova-Babayan 1987), threatening poplar-producing regions around the world.

The economic importance of Sphaerulina musiva has led to several studies evaluating the efficacy of chemical and cultural control; however, these measures were found to be only partially effective and not economically feasible in commercial plantations (Gyenis et al. 2003; Ostry 1987). As a result, the only economically and ecologically viable approach is the development and deployment of disease-resistant genotypes (Ostry 1987). Although P. nigra is used in hybrid poplar breeding programs in the United States (Bisoffi and Gullberg 1996), to our knowledge, there is no information available on its resistance to Septoria canker. Given that $P$. nigra and $S$. musiva have not coevolved together, it is essential to determine whether variation in resistance to Septoria canker exists in $P$. nigra in order to develop a successful breeding program. To meet this goal, cuttings from 47 genotypes of $P$. nigra from several locations across its geographic range were collected and inoculated, under greenhouse conditions, with six isolates of $S$. musiva from the north-central United States. The specific objectives of this study were to (i) characterize the variability in resistance of $P$. nigra among and within locations using the parameters cankers per centimeter and disease severity score; (ii) determine whether location, isolate, genotype, or their interactions significantly affect variation in these two parameters; and (iii) examine the correlation in disease severity score between single-isolate and bulk-isolate inoculations.

\section{Materials and Methods}

Experiment 1. Poplar culture. Through the cooperation of colleagues involved in breeding and gene conservation in Europe, open-pollinated seed was obtained by sampling female $P$. nigra from 15 different mother trees at seven locations in Europe (Fig. 1). Seeds were germinated and grown in the greenhouse and cuttings of 460 clones were planted at the Belle River archival plantation in Minnesota 
$\left(45.97^{\circ} \mathrm{N}, 95.19^{\circ} \mathrm{W}\right)$ in 2009 . Dormant $P$. nigra cuttings were collected from 47 randomly selected genotypes in late January 2013 from branches. These cuttings were cut into $10-\mathrm{cm}$ lengths with a bud at the top of each cutting and stored at approximately $0^{\circ} \mathrm{C}$ until planting. Cuttings were soaked in water for $48 \mathrm{~h}$ at room temperature (DesRochers and Thomas 2003), planted in cone-tainers (Ray Leach SC10 Super Cone-tainers; Stuewe and Sons, Inc., Tangent, OR) measuring $3.8 \mathrm{~cm}$ in diameter and $21 \mathrm{~cm}$ deep filled with growing medium (SunGro Professional Mix number 8; SunGro Horticulture Ltd., Agawam, MA) amended with $12 \mathrm{~g}$ of Nutricote slow-release fertilizer (15-9-12, $\mathrm{N}-\mathrm{P}-\mathrm{K} ; 7.0 \% \quad \mathrm{NH}_{3}-\mathrm{N}, 8.0 \% \quad \mathrm{NO}_{3}-\mathrm{N}, 9.0 \% \quad \mathrm{P}_{2} \mathrm{O}_{5}, 12.0 \% \quad \mathrm{~K}_{2} \mathrm{O}$, $1.0 \% \mathrm{Mg}, 2.3 \% \mathrm{~S}, 0.02 \% \mathrm{~B}, 0.05 \% \mathrm{Cu}, 0.45 \% \mathrm{Fe}, 0.23 \%$ chelated $\mathrm{Fe}, 0.06 \% \mathrm{Mn}, 0.02 \% \mathrm{Mo}$, and $0.05 \% \mathrm{Zn}$; Scotts Osmocote Plus; Scotts Company Ltd., Marysville, $\mathrm{OH}$ ). The cuttings were planted such that the topmost bud remained above the surface of the growing medium. There were 25 cone-tainers per rack. Plants were grown in a greenhouse with a temperature regime of 20 and $16^{\circ} \mathrm{C}$ (day and night, respectively) and an 18-h photoperiod supplemented with $600-\mathrm{W}$ high-pressure sodium lamps. Slow-release fertilizer was enhanced weekly with 15-30-15 (N-P-K) Jack's fertilizer (JR Peters Inc., Allentown, PA) at $200 \mathrm{ppm}$ for 2 months to promote root growth, and subsequently fertilized with 20-20-20 (N-P-K) liquid fertilizer (Scotts Peters Professional; Scotts Company Ltd.) once a week. Plants were watered as needed.

Pathogen culture. S. musiva was isolated from individual branch cankers (MN-12, MN-22, MN-14, MN-16, and MN-32) collected from a commercial fiber farm nursery near Belle River in Minnesota $\left(45.97^{\circ} \mathrm{N}, 95.19^{\circ} \mathrm{W}\right)$ and the North Dakota State University campus (Nisk1). Cankers were soaked for $2 \mathrm{~min}$ in a $5 \% \mathrm{NaClO}$ solution and rinsed twice with sterile distilled water. After removing the bark from the stem, a 5-mm sliver of tissue was excised from the margin between necrotic and healthy tissue. These slivers were placed on petri plates containing KV-8 medium (180 ml of V-8 vegetable juice [Campbell Soup Company, Camden, NJ], $2 \mathrm{~g}$ of calcium carbonate, $20 \mathrm{~g}$ of agar, and $820 \mathrm{ml}$ of deionized water) (Stanosz and Stanosz 2002) amended with chloramphenicol (Chloramphenicol USP; Amresco,
$\mathrm{OH})$ at $240 \mathrm{mg}$ liter $^{-1}$ and streptomycin (Streptomycin Sulfate USP; Amresco) at $100 \mathrm{mg} \mathrm{liter}^{-1}$. Petri plates were wrapped with Parafilm, placed on a light bench, and grown under continuous light at room temperature $\left(20^{\circ} \mathrm{C}\right)$. Seven days later, the fungal colonies that were sporulating were transferred to new $\mathrm{KV}-8$ petri plates. The fungus was identified based on its morphology (Sivanesan 1990) and species identity was confirmed by multilocus genotyping (Leboldus et al. 2015). All isolates were stored in 2-ml cryotubes at $-80^{\circ} \mathrm{C}$ as mycelial plugs suspended in a $50 \%$ glycerol solution. Approximately 2 weeks prior to inoculation, six isolates were poured onto KV-8 petri plates. After 4 days, each isolate was subcultured onto 20 plates by placing five 5-mm masses of sporulating mycelium onto new $\mathrm{KV}-8$ petri plates which were subsequently sealed with Parafilm.

Inoculation. After S. musiva isolates were grown on K-V8 media for approximately 12 days under continuous light, a spore suspension was prepared by flooding each plate with $5 \mathrm{ml}$ of distilled water, rubbing the surface with a sterile inoculation loop to dislodge the spores, and removing the resulting spore suspension with a micropipette. The spore suspensions from all plates for each isolate were combined and the concentration corrected to $1 \times 10^{6}{\text { conidia } \mathrm{ml}^{-1}}^{-1}$ (LeBoldus et al. 2010). Approximately $250 \mathrm{ml}$ of each isolate was used to inoculate all 47 trees in each block. Prior to inoculation, the height of the stem was measured. The entire tree was sprayed until runoff and each rack of trees was sealed in a separate black plastic bag for $48 \mathrm{~h}$. The control trees were sprayed with distilled water in the same manner. At $48 \mathrm{~h}$ after inoculation, the trees were removed from the bags and placed back into the greenhouse.

At 21 days postinoculation, the number of cankers (necrotic lesions) was counted and disease severity score was estimated using a 1-to-5 scale, where $1=$ no lesions, $2=$ small necrotic lesions with swollen margins, $3=$ small necrotic lesions, $4=$ large necrotic lesions, and $5=$ stem girdled by lesions or sporulating lesions. This scale was adapted from LeBoldus et al. (2007). Cankers per centimeter was calculated by taking the number of stem lesions divided by the height of the tree at the time of inoculation.

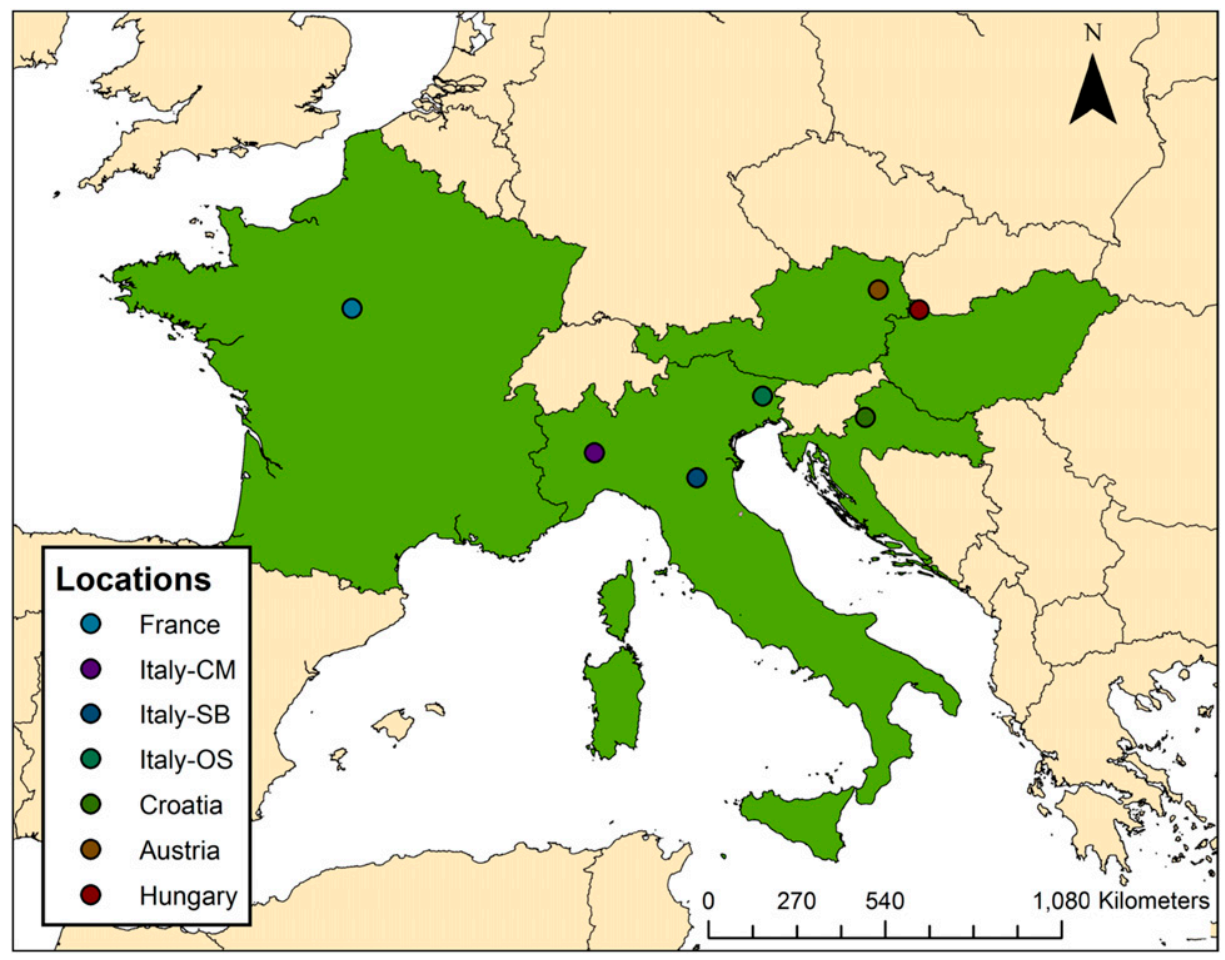

Fig. 1. Map of open-pollinated Populus nigra seed collection locations in Europe. The countries from which seed were collected included Austria $(n=8)$, Croatia $(n=3)$, France $(n=8)$, Hungary $(n=5)$, and three separate locations in Italy: Italy-CM $(n=3)$, Italy-OS $(n=16)$, and Italy-SB $(n=4)$. The genotype number $(n)$ represents the number of genotypes, collected as dormant hardwood cuttings, from the Belle River Archival plantation in Minnesota. 
Experimental design. The experimental design was a randomized complete block design with four blocks. Seven treatments comprising the six different isolates and a distilled water control were used to inoculate 47 different $P$. nigra genotypes. Trees were arranged such that the 47 genotypes inoculated with each isolate were randomly arranged within two racks. Each rack was placed in a separate bag following inoculation. This design resulted in a total of 1,316 plants for this experiment.

Data analysis. A random-effects model using the mixed procedure in SAS 9.3 (SAS Institute, Cary, NC) was used to analyze the effect of treatment on cankers per centimeter and disease severity score (Littell et al. 2006). Statistical significance was assessed at $\alpha=0.05$. Model selection was conducted using the likelihood ratio $\chi^{2}$ test to determine the significance of each of the parameters, including block, location, isolate, genotype(location), and genotype(location) $\times$ isolate. The order of testing was determined based on the magnitude of the default $z$ test; the parameter with the largest value was tested first. In each subsequent model, nonsignificant parameters were removed. The final model was used to determine the proportion of the variance that each parameter contributed to the model. The same analysis was conducted for the two variables (cankers per centimeter and disease severity score) independently.

The initial model for both parameters was $Y_{i j k l}=\mu+\beta_{i}+I_{j}+L_{k}+$ $G_{l}\left(L_{k}\right)+I_{j} \times G_{l}\left(L_{k}\right)+\varepsilon_{i j k l}$, where $Y_{i j k l}$ is the disease severity score or cankers per centimeter value in the $i$ th block for the $l$ th genotype nested within the $k$ th location, inoculated with the $j$ th isolate; $\mu$ is the overall mean; $\beta_{i}$ is the random effect of the $i$ th block, $i=1$ to $4 ; I_{j}$ is the random effect of the $j$ th isolate, $j=1$ to $6 ; L_{k}$ is the random effect of the $k$ th location, $k=1$ to $7 ; G_{l}\left(L_{k}\right)$ is the random effect of the $l$ th genotype nested within the $k$ th location, $l=1$ to $47 ; I_{j} \times G_{l}\left(L_{k}\right)$ is the $j$ th isolate by $l$ th genotype nested within the $k$ th location interaction; and $\varepsilon_{i j k l}$ is the residual error. Location means were compared using the best linear unbiased predictors (BLUP) and the $95 \%$ prediction intervals that were generated by the estimate statement in SAS 9.3 (Littell et al. 2006).

Experiment 2. Thirteen genotypes, exhibiting a range of disease severities ( 1 to 5 ) in experiment 1 , were selected for the second experiment. Ten trees of each genotype were planted in 2-gal. pots filled with growing medium (SunGro Professional Mix number 8; SunGro Horticulture Ltd.) amended with $38 \mathrm{~g}$ of Osmocote Nutricote slow-release fertilizer (15-9-12). When the plants reached a height of $30 \mathrm{~cm}$, they were inoculated as described above, with the sole exception that inoculations were conducted with a bulk spore suspension of all six isolates rather than single isolates. The bulk spore suspension was made by adjusting the spore concentration of each isolate and then combining equal volumes of each spore suspension (LeBoldus et al. 2010). The experimental design was a randomized complete block design with 10 blocks. Each genotype occurred once per block. The tenth block was a control and was sprayed with distilled water. After 3 weeks, disease severity score and cankers per centimeter were recorded and the data were analyzed in the same manner as in the first experiment. In addition, the CORR procedure in SAS was used to compare the cankers per centimeter and disease severity score values between the two experiments. This was done in order to determine whether the average disease severity (cankers per centimeter or disease severity score) of a genotype when inoculated with a single isolate was correlated to the average disease severity of the same genotype when inoculated with a bulk spore suspension. At the end of the experiment, 18 cankers were collected and S. musiva was reisolated from the stems.

\section{Results}

Dark-brown necrotic lesions were observed between 2 and 3 weeks postinoculation. Lesions first appeared as sunken, discolored areas on the stem which varied in size and shape but were mainly elliptical, becoming dark brown in color. More resistant genotypes had necrotic lesions with swollen margins, while more susceptible genotypes had rapidly expanding lesions usually lacking swollen margins. Most of the necrotic lesions appeared on the lower third of the stem, centered around lenticels or stipule scars. No symptoms occurred on any controls used in the experiments and the controls were not included in any statistical analysis. S. musiva was successfully reisolated from 5 of 18 cankers.

Experiment 1. Cankers per centimeter. The final model for cankers per centimeter included the random effects of block $(P=0.121)$, location $(P<0.001)$, and genotype(location) $(P<0.001)$ (Table 1$)$. The majority of the variation was explained by location $(72 \%)$, followed by genotype(location) (28\%) (Table 1$)$. The cankers per centimeter values ranged from 0.010 to 0.108 . A comparison of the BLUP for locations indicated that Austria and Hungary had significantly greater cankers per centimeter values then the remaining locations (Fig. 2).

Disease severity score. The final model for disease severity score included all random factors: block $(P<0.001)$, isolate $(P=0.034)$, location $(P=0.025)$, genotype(location) $(P<0.001)$, and the genotype (location) $\times$ isolate interaction $(P=0.004)$ (Table 1$)$. The majority of the variation was explained by genotype(location) (51\%) followed by location $(26 \%)$ (Table 1$)$. The significant genotype(location) $\times$ isolate interaction explained $15 \%$ of the variability and the isolate effect explained $3.2 \%$ of the variability (Table 1 ). The average disease severity score ranged from 1.303 to 3.087. A comparison of the BLUP for disease severity score among locations indicates that Austria had a significantly greater disease severity score than France, IT-OS, and IT-SB but was similar to Croatia, Hungary, and IT-CM (Fig. 3).

Experiment 2. The average cankers per centimeter ranged from 0.012 to 0.254 and the average disease severity score ranged from 1.556 to 4.667 . The Pearson correlation coefficients indicated a significant correlation between the two experiments for both cankers per centimeter $(r=0.89)$ and disease severity score $(r=0.93)$ when averaged across all isolates. The correlations between each isolate in experiment 1 and bulk-isolate inoculations from experiment 2 ranged from 0.871 to 0.952 (Table 2) and exhibited similar trends to that depicted in Figure 4.

\section{Discussion}

This is the first study describing the variation in resistance to $S$. musiva in a population of $P$. nigra, a commonly used parent in hybrid poplar breeding programs in the north-central United States. Lesions that developed in the current study were similar to previous reports in the literature in terms of their appearance and location (LeBoldus et al. 2010; Long et al. 1986; Qin et al. 2014; Zalasky 1978). The majority of studies evaluating disease resistance in other

Table 1. Final models for cankers per centimeter and disease severity score ${ }^{\mathrm{a}}$

\begin{tabular}{|c|c|c|c|c|c|c|c|}
\hline \multirow[b]{2}{*}{ Source of variation } & \multirow[b]{2}{*}{ df } & \multicolumn{3}{|c|}{ Cankers per centimeter } & \multicolumn{3}{|c|}{ Disease severity score } \\
\hline & & Estimate & $P$ & Proportion & Estimate & $P$ & Proportion \\
\hline Block & 3 & 0.000 & 0.121 & 0.45 & 0.024 & $<0.001$ & 5.56 \\
\hline Isolate & 5 & $\ldots$ & 0.157 & $\ldots$ & 0.014 & 0.034 & 3.20 \\
\hline Location & 6 & 0.002 & $<0.001$ & 71.89 & 0.110 & 0.025 & 25.85 \\
\hline Genotype(location) & 322 & 0.001 & $<0.001$ & 27.66 & 0.215 & $<0.001$ & 50.58 \\
\hline Isolate $\times$ genotype(location) & 1,610 & $\ldots$ & 0.999 & $\ldots$ & 0.063 & 0.004 & 14.80 \\
\hline Error & 5,950 & 0.010 & $\ldots$ & $\ldots$ & 1.180 & $\ldots$ & $\ldots$ \\
\hline Total & 7,896 & $\ldots$ & $\ldots$ & 100 & $\ldots$ & $\ldots$ & 100 \\
\hline
\end{tabular}

a Source of variation, degrees of freedom (df), variance estimates, $P$ values $(P)$, and proportion of explained variation for disease severity score and cankers per centimeter for each random variable tested in each model. 
Populus spp. and hybrids artificially inoculated with $S$. musiva have reported differences among genotypes in terms of either canker severity (similar to disease severity score) (LeBoldus et al. 2007, 2008, 2009; Ward and Ostry 2005) or infection frequency (cankers per centimeter) (LeBoldus et al. 2010), with the sole exception of Qin et al. (2014), who reported both. Typically, this division is based on the type of inoculation procedure used. In the case of wound inoculations, disease severity score is frequently used to compare host responses to pathogen development following inoculation (LeBoldus et al. 2007; Weiland et al. 2003) whereas, when whole trees are inoculated with a spore suspension, cankers per centimeter is typically reported (LeBoldus et al. 2010). Both of these measures have provided useful information; however, Qin et al. (2014) demonstrated that, in order to accurately predict long-term survival in the field, (i) an estimate of infection frequency and (ii) a measure of disease severity are essential. To this end, resistance was evaluated in terms of both cankers per centimeter and disease severity score in this study.

Separate analyses of the data using the different response variables revealed several interesting patterns in terms of which factors significantly contributed to the variation and how that variation was partitioned among sources (Table 1). For example, in both models, location and genotype(location) were significant sources of variation (Table 1). However, in the cankers per centimeter model, the majority of the variation was explained by the location (72\%) effect, with genotype(location) (28\%) explaining less. In contrast, in the disease severity score model, the majority of the variation was explained by genotype(location) $(51 \%)$ rather than location (26\%) (Table 1).

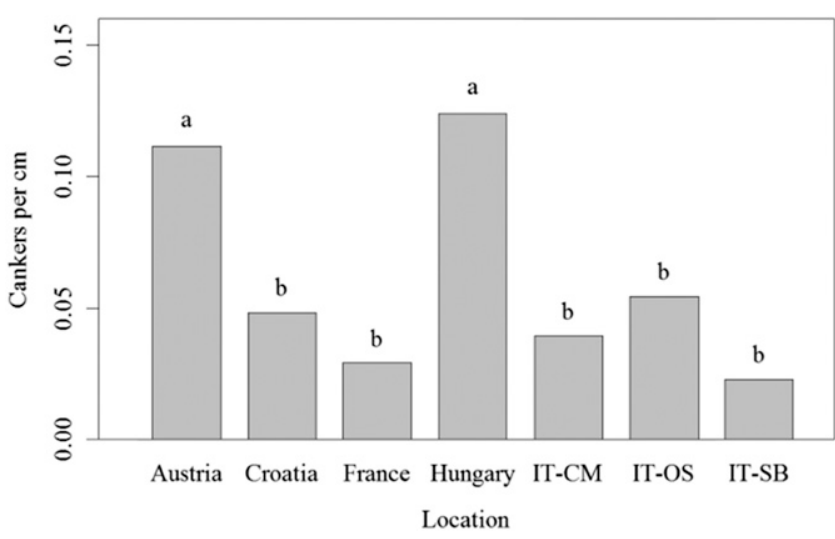

Fig. 2. Disease severity as measured by the average cankers per centimeter of all genotypes for each location. Locations with different letters are significantly different based on their $95 \%$ prediction intervals. Locations beginning in IT are distinct locations within Italy.

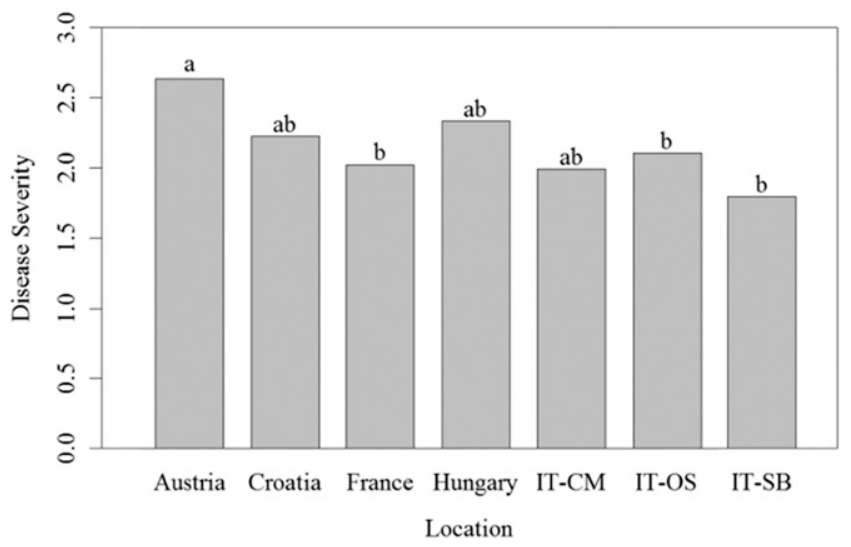

Fig. 3. Disease severity as measured by the average disease severity score (1 to 5 ) for all the genotypes from each location. Locations with different letters are significantly different based on their $95 \%$ prediction intervals. Locations beginning in IT are distinct locations within Italy.
One possible explanation for these differences may be that cankers per centimeter and disease severity score are measuring resistance at different stages in the infection process. The cankers per centimeter parameter estimates infection frequency by counting lesion number, whereas the disease severity score parameter evaluates disease severity or pathogen development following infection based on lesion size.

A second possible explanation for the differences in the models may be related to the infection court used by the pathogen. Qin and LeBoldus (2014) demonstrated that $S$. musiva penetrates host tissue via lenticels, stipule scars, and other natural openings. When considering the pattern of variation described above, it is possible that lenticel frequency and morphology, both important for successful infection of Populus spp. by S. musiva, have greater variation within populations compared with among populations. A similar pattern was observed in a study looking at evolutionary trade-offs of stomatal trait variation in P. trichocarpa (McKown et al. 2014), which found that the variation, in terms of adaxial stomata number, was highly correlated to increased susceptibility to Melampsora rust. It is important to note that a study examining the frequency and morphology of lenticels would need to be conducted to test this hypothesis.

A comparison of the disease severity score and cankers per centimeter models indicated that there was a significant isolate effect when the data were analyzed using disease severity score as the response variable (Table 1). The significance of this effect may have implications for disease resistance breeding and greenhouse screening in terms of which isolates and how many are used to screen for resistance. For example, several authors have suggested

Table 2. Pearson correlation coefficient comparing the single-spore inoculations with the bulk inoculations ${ }^{\mathrm{a}}$

\begin{tabular}{lc}
\hline Isolate & Pearson \\
\hline 1 & 0.871 \\
2 & 0.913 \\
3 & 0.952 \\
4 & 0.916 \\
5 & 0.921 \\
6 & 0.918 \\
\hline${ }^{a}$ Correlations were calculated based on the average disease severity score for \\
each isolate (1 to 6) from experiment 1 compared with the bulk isolates from \\
experiment 2.
\end{tabular}

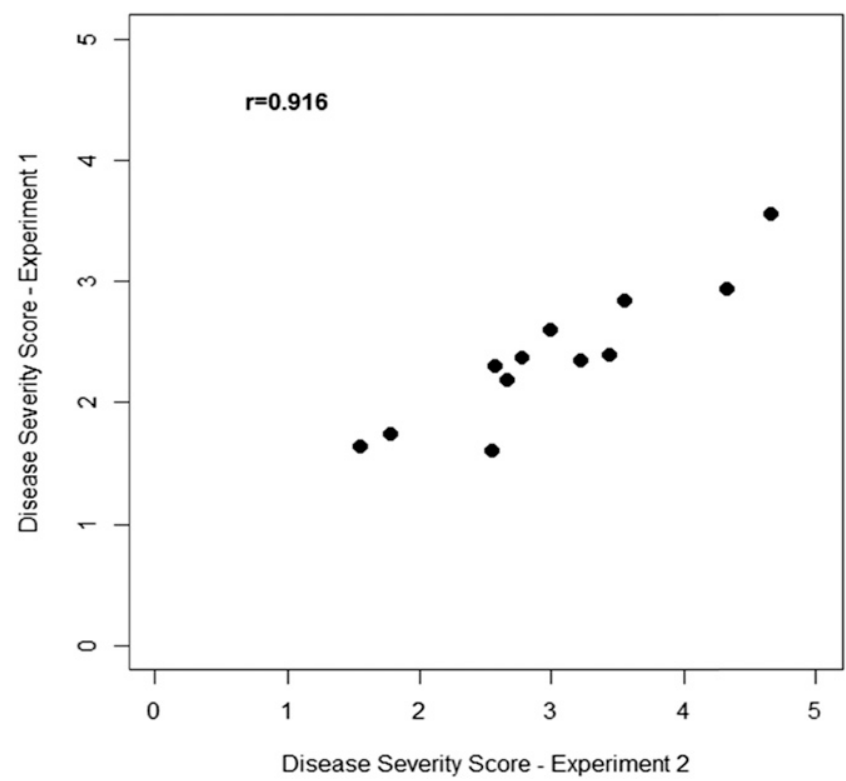

Fig. 4. Correlation of isolate 4 in experiment 1 and the bulk spore suspension of all isolates in experiment 2 for the average disease severity score. Each dot represents a different genotype. The $r$ value represents the Pearson correlation coefficient. All isolates exhibited similar patterns. 
(LeBoldus et al. 2008; Qin et al. 2014; Ward and Ostry 2005) that a single highly virulent isolate would be sufficient to identify the most resistant and susceptible genotypes. Although this study focuses on a small, geographically restricted pathogen population, the strong correlations observed when comparing the disease severity score values from experiment 1 (single-isolate inoculations) to the disease severity score values in experiment 2 (bulk-isolate inoculations), and when comparing the cankers per centimeter across both experiments supports this idea. However, it is important to note that Feau et al. (2005) detected evidence for sexual reproduction and genetic differentiation at the regional level among isolates of $S$. musiva. This genetic analysis combined with the small but significant genotype (location) $\times$ isolate interaction, detected when disease severity score was used as a response variable (Table 1), suggest that the potential exists for shifts in virulence in the isolate population over time.

The study described above clearly demonstrates that $P$. nigra is susceptible to $S$. musiva and that variation within the host population exists (Table 1). In order to effectively exploit the variation in resistance to $S$. musiva characterized by this study, a better understanding of the genetics of susceptibility and how that susceptibility is inherited in hybrid progeny is essential. However, until this is achieved, the best strategy for breeding programs is to identify and use the most resistant genotypes as parents when producing hybrid progeny. In general, the susceptibility of $P$. nigra described above highlights the importance of preventing the introduction of $S$. musiva into Europe, where stands of $P$. nigra are a valuable riparian habitat in need of conservation.

\section{Acknowledgments}

This study was supported by the United States Department of Agriculture National Institute of Food and Agriculture USDA-NIFA-RIPM 2012-3410319771 grant. Work on collection and establishment of field tests was supported by the United State Department of Energy, Sun Grant Initiative Regional Biomass Feedstock Partnership through a subcontract from South Dakota State University. A Graduate Research Assistantship was provided to K. L. Dunnell from North Dakota State University-Agriculture Experiment Station. We thank J. Walla, A. Nepal, R. Qin, and L. Rasmussen for technical assistance.

\section{Literature Cited}

Ares, A., and Gutierrez, L. 1996. Selection of poplar clones for the lower valley of the Colorado River, Argentina. Forestry 69:75-82.

Bier, J. E. 1939. Septoria canker of introduced and native hybrid poplars. Can. J. Res. 17c(6): 195-204

Bisoffi, S., and Gullberg, U. 1996. Poplar breeding and selection strategies. Pages 139-155 in: Biology of Populus and Its Implications for Management and Conservation. R. F. Stettler, H. D. Bradshaw, Jr., P. E. Heilman, and T. M. Hinckley, eds. NRC Research Press, Ottawa, ON, Canada.

Callan, B. E., Leal, I., Foord, B., Dennis, J. J., and Van Oosten, C. 2007. Septoria musiva isolated from cankered stems in hybrid poplar stool beds, Fraser Valley, British Columbia. North Am. Fungi. 2:1-9.

DesRochers, A., and Thomas, B. R. 2003. A comparison of pre-planting treatments on hardwood cuttings of four hybrid poplar clones. New For. 26:17-32.

Dickmann, D. I., Isebrands, J. G., Eckenwalder, J. E., and Richardson, J. 2001. Poplar Culture in North America. NRC Research Press, Ottawa, ON, Canada.

Feau, N., Hamelin, R. C., Vandecasteele, C., Stanosz, G. R., and Bernier, L. 2005. Genetic structure of Mycosphaerella populorum (anamorph Septoria musiva) populations in north-central and northeastern North America. Phytopathology 95:608-616.

Feau, N., Mottet, M. J., Périnet, P., Hamelin, R. C., and Bernier, L. 2010. Recent advances related to poplar leaf spot and canker caused by Septoria musiva. Can. J. Plant Pathol. 32:122-134.
Gyenis, L., Anderson, N. A., and Ostry, M. E. 2003. Biological control of Septoria leaf spot disease of hybrid poplar in the field. Plant Dis. 87:809-813.

LeBoldus, J. M., Blenis, P. V., and Thomas, B. R. 2007. Evaluating the interaction between genotype and water stress in the hybrid poplar-Septoria musiva pathosystem. Can. J. Bot. 85:1098-1102.

LeBoldus, J. M., Blenis, P. V., and Thomas, B. R. 2008. Clone by isolate interaction in the hybrid poplar-Septoria musiva pathosystem. Can. J. Res. 38:1888-1896.

LeBoldus, J. M., Blenis, P. V., and Thomas, B. R. 2010. A method to induce stem cankers by inoculating nonwounded Populus clones with Septoria musiva spore suspensions. Plant Dis. 94:1238-1242.

LeBoldus, J. M., Blenis, P. V., Thomas, B. R., Feau, N., and Bernier, L. 2009. Susceptibility of Populus balsamifera to Septoria musiva: A field study and greenhouse experiment. Plant Dis. 93:1146-1150.

Leboldus, J. M., Kinzer, K., Richards, J., Ya, Z., Yan, C., Friesen, T. L., and Brueggeman, R. 2015. Genotype-by-sequencing of the plant-pathogenic fungi Pyrenophora teres and Sphaerulina musiva utilizing Ion Torrent sequence technology. Mol. Plant Pathol. 16:623-632.

Littell, R. C., Milliken, G. A., Stroup, W. W., Wolfinger, R. D., and Schabenberger, O. 2006. SAS for Mixed Models, 2nd ed. SAS Institute Inc., Cary, NC.

Lo, M. H., Abrahamson, L. P., White, E. H., and Manion, P. D. 1995. Early measures of basal area and canker disease predict growth potential of some hybrid poplar clones. Can. J. Res. 25:1113-1118.

Long, R., Bowersox, T. W., and Merrill, W. 1986. Artificial inoculation of Populus hybrids with Septoria musiva. Can. J. Res. 16:405-407.

McKown, A. D., Guy, R. D., Quamme, L., Klápště, J., La Mantia, J., Constabel, C. P., El-Kassaby, Y. A., Hamelin, R. C., Zifkin, M., and Azam, M. S. 2014 Association genetics, geography and ecophysiology link stomatal patterning in Populus trichocarpa with carbon gain and disease resistance trade-offs. Mol. Ecol. 23:5771-5790.

Newcombe, G., and Ostry, M. 2001. Recessive resistance to Septoria stem canker of hybrid poplar. Phytopathology 91:1081-1084.

Ostry, M. E. 1987. Biology of Septoria musiva and Marssonina brunnea in hybrid Populus plantations and control of Septoria canker in nurseries. Eur. J. For. Pathol. 17:158-165.

Ostry, M. E., and McNabb, H. S., Jr. 1985. Susceptibility of Populus species and hybrids to disease in the north central United States. Plant Dis. 69: 755-757.

Qin, R., and LeBoldus, J. M. 2014. The infection biology of Sphaerulina musiva: Clues to understanding a forest pathogen. PLoS One 9:e103477.

Qin, R., Stanosz, G. R., and LeBoldus, J. M. 2014. A nonwounding greenhouse screening protocol for prediction of field resistance of hybrid poplar to Septoria canker. Plant Dis. 98:1106-1111.

Santos, Á. F. D., Machado, E. B., Stanosz, G. R., and Smith D. R. 2010. First report of Septoria musiva in poplar in Brazil. Trop. Plant Pathol. 35: 052-053.

Sivanesan, A. 1990. Mycosphaerella populorum. CMI description of pathogenic fungi and bacteria, no 988. Mycopathologia 109:57-58.

Stanosz, J. C., and Stanosz, G. R. 2002. A medium to enhance identification of Septoria musiva from poplar cankers. For. Pathol. 32:145-152.

Teterevnikova-Babayan, D. N. 1987. Fungi of the genus Septoria in the U.S.S.R Akademiya Nauk Armyanskoi. Yerevan, Armenian SSR.

Ward, K. T., and Ostry, M. E. 2005. Variation in Septoria musiva and implications for disease resistance screening of poplars. Plant Dis. 89: 1077-1082.

Waterman, A. M. 1954. Septoria canker of poplars in the United States. U.S. Dep. Agric. Circ. No. 947:1-22.

Weiland, J. E., and Stanosz, G. R. 2003. Epidemic of canker disease on hybrid poplar clone NM6. (Abstr.) Phytopathology 93:S89.

Weiland, J. E., Stanosz, J. C., and Stanosz, G. R. 2003. Prediction of long-term canker disease damage from the responses of juvenile poplar clones to inoculation with Septoria musiva. Plant Dis. 87:1507-1514.

Zalasky, H. 1978. Stem and leaf spot infections caused by Septoria musiva and S. populicola on poplar seedlings. Phytopathology 59:43-50. 